\title{
EchoGéo
}

48 | 2019

Illegal cannabis cultivation in the world

\section{Cannabis cultivation in the world: heritages, trends and challenges}

Pierre-Arnaud Chouvy

\section{OpenEdition}

1 Journals

Electronic version

URL: https://journals.openedition.org/echogeo/17591

DOI: 10.4000/echogeo.17591

ISSN: 1963-1197

\section{Publisher}

Pôle de recherche pour l'organisation et la diffusion de l'information géographique (CNRS UMR 8586)

\section{Electronic reference}

Pierre-Arnaud Chouvy, "Cannabis cultivation in the world: heritages, trends and challenges", EchoGéo [Online], 48 | 2019, Online since 13 July 2019, connection on 31 July 2021. URL: http:// journals.openedition.org/echogeo/17591 ; DOI: https://doi.org/10.4000/echogeo.17591

This text was automatically generated on 31 July 2021.

EchoGéo est mis à disposition selon les termes de la licence Creative Commons Attribution - Pas d'Utilisation Commerciale - Pas de Modification 4.0 International (CC BY-NC-ND) 


\title{
Cannabis cultivation in the world: heritages, trends and challenges
}

\author{
Pierre-Arnaud Chouvy
}

Acknowledgements: For helpful comments on an earlier draft I am indebted to Laurent Appel, Chris Duvall, Jennifer Macfarlane, and anonymous reviewers.

1 Despite cannabis being the most common illegal drug crop in the world and its worldwide presence, very little is known about its production, trade, and consumption at the global scale. This is partly due to the fact that knowledge about cannabis cultivation is lacking in many countries and regions, even in some the oldest and largest producing areas. For example, notwithstanding the historical importance and volumes of their cannabis productions, there is very limited knowledge of the cannabis cultivation's contexts, drivers, and recent trends in countries such as Afghanistan, Albania, Colombia, the Democratic Republic of Congo, India, Jamaica, Lebanon, Ghana, Mexico, etc.

2 This is partly explained by geographer Chris Duvall when he writes that "Cannabis has been mostly prohibited worldwide since the 1930s, which has stunted formal, scholarly research on the plant, including scientific taxonomy". Which is why, he writes, "although there are a few formally trained Cannabis experts, in current global society most experts are informally trained, whether marihuana aficionados, hemp activists or anti-drug crusaders" (Duvall, 2014, p. 13). Indeed, as explained by the botanist and cannabis specialist Ernest Small, because of cannabis' "criminal association", almost all research and economic development - both narcotic and non-narcotic aspects - were suppressed for most of the 20th century" (Small, 2015, p. 190). As a result, a "truly glaring gap on cannabis production, distribution, and consumption" exists in the geographic literature on drug commodities and "cannabis, including hemp and its psychoactive counterpart, has a long but largely overlooked historical geography" (Taylor et al., 2013, p. 425-426; Warf, 2014, p. 414).

3 In this text I examine the knowns and unknowns of cannabis cultivation in the world in an effort to bridge some of the gaps on cannabis production. I first explain how complex and controversial Cannabis taxonomy is, and how much confusion still 
surrounds the use, by botanists and aficionados, of the sativa and indica taxa. I then resort to a historical approach to describe how much cannabis cultivation and production techniques have evolved since the 1960s and what the various traditional and modern cannabis by-products are. Only then do I focus on what we know and don't know (and how) about global cannabis cultivation. I conclude that while much still needs to be learned about the past and even the present of cannabis production and uses in the world, the real urgency lies in understanding what the future holds now that legalisation is well under way and is spreading fast throughout the world.

\section{What Cannabis species, varieties, and strains?}

4 Pretty much everything about the cannabis plant leads to controversial debates, including its taxonomic classification. Considering the large knowledge deficit on cannabis cultivation in the world, how the name cannabis is used instinctively to refer to very different varieties/strains with extremely variable potencies ${ }^{1}$ and yields, how deeply the cannabis industry has changed in the past years (increased importance of high-yielding varieties/strains, development of modern production techniques) (Chouvy and Afsahi, 2014; Clarke and Merlin, 2016; Chouvy and Macfarlane, 2018), and how it is being affected by legislative debates and changes (decriminalisation and legalisation), it is important to acknowledge that simply speaking of "cannabis" to refer indistinctively to a low-potency landrace or a high-potency and high-yield modern hybrid, or referring to the traditional distinction between Cannabis sativa and Cannabis indica is often vague, unscientific, and confusing. Also, very few authors, outside of cannabis aficionados and experts, fully understand the complexity of cannabis diversity and distinguish clearly between landraces, heirlooms, hybrids (not genetically modified organisms as can be sometimes inaccurately reported), varieties, strains, all-female seeds, sinsemilla, etc.

The confusion actually starts with the fact that the very botany of the Cannabis genus is still controversial. Indeed, despite being one the world's oldest crops (hemp was already harvested in China 8500 years ago), whether the genus Cannabis is monotypic (one species, as argued by Small) or polytypic (up to three species, as argued by Emboden, Hillig, and Clarke and Merlin) has been uncertain since Linnaeus described a single species (Cannabis sativa, in 1753) and Lamarck proposed two species (Cannabis sativa and Cannabis indica in 1785) (Schultes et al., 1975; Emboden, 1981; Hillig, 2005, Clarke and Merlin, 2013; Small, 2015, p. 218). This is in part due to the plant's ancient origin, to its extremely long evolutionary and domestication history (including artificial selection) that is responsible for the probable disappearance of wild populations, and to its widespread geographic dispersal (cultivated and ruderal varieties). Since prohibition has long prevented most scientific enquiries, both the taxonomic separation of the putative taxa C. sativa and C. indica and the plant's phylogeny have remained highly controversial until now, so much that a more modern taxonomic treatment of Cannabis originally devised by Karl Hillig was recently further developed by Robert Clarke and Mark Merlin who argue that the "present-day genetic distinction is essentially "dope versus rope" or narrow-leaf drug (NLD) and broad-leaf drug (BLD) biotypes (both indica) versus a narrow-leaf hemp (NLH) biotype (a sativa) (Schultes et al., 1975; Small and Cronquist, 1976; Hillig, 2005; Clarke and Merlin, 2013; Small, 2015). 
6 Therefore, the place of Cannabis in the International Code of Nomenclature for Algae, Fungi, and Plants (ICN) is not clear since botanists still strongly disagree about how many species and subspecies of Cannabis exist. Also, to the difference of hemp cultivars (such as the twenty-four most common fibre hemp cultivars that existed in 1995: Meijer, 1995), the thousands of marihuana ${ }^{2}$ strains (2,494 "unique" strains as of June 2018 and 2,942 as of June 2019 according to Leafly ${ }^{3}$ cannot be included in the International Code of Nomenclature for Cultivated Plants (ICNCP) as they were and are still being created by mostly clandestine breeders and lack the stability and reliability required in order to be officially considered as cultivars (Small 2015; Sawler et al. 2015). In any case, drug cannabis strains are biologically but not nomenclaturally equivalent to non-drug cannabis (hemp) cultivars and as such they only bear vernacular names (such as Skunk \#1, the first modern cannabis hybrid) (Small, 2015, p. 271).

7 This is why it is difficult at this stage, despite what most botanists and cannabis aficionados do, to indisputably apply the sativa/indica taxa (it is not mandatory according to the ICNCP) to the genus Cannabis without adding to the existing confusion. As explained by Ernest Small in his recent extensive monograph on the genus Cannabis, "taxonomists have utilised the epithets sativa and indica to distinguish two taxa, the term sativa traditionally designating non-narcotic plants in contrast to the term indica which has been used to designate narcotic plants". Yet, in the largely illegal cannabis trade, "sativa" and "indica" labels (not taxa and as such not italicised) are used "for different classes of narcotic plants, and (contradictory to taxonomic tradition)" with the term sativa designating plants with very high $\mathrm{THC}^{4}$ content and low or no $\mathrm{CBD}^{5}$ content, and the term indica designating plants with moderate to high THC content and moderate to high CBD content (Small, 2015, p. 262).

However, the vernacular use of the sativa/indica labels by the marihuana industry and community seems to be as controversial as the taxonomic separation between the putative taxa C. sativa and C. indica, as shown by a 2015 study that looked at 81 marihuana and 41 hemp samples and found that the sativa/indica labels of marihuana strain names "often do not reflect a meaningful genetic identity" and that "hemp is genetically more similar to C. indica type marijuana than to C. sativa strains". As the authors explain, "the inaccuracy of reported ancestry in marijuana likely stems from the predominantly clandestine nature of Cannabis growing and breeding over the past century" (Sawler et al., 2015).

9 In any case, molecular genetics is providing increasing evidence that Cannabis is a polytypic genus, thereby leading credence to the in-field observations ${ }^{6}$ made by most of the partisans of the polytypic theory: as stressed by William Emboden, a hiatus exists between biologists, botanists, or taxonomists who have conducted direct observations in the field (such as in Afghanistan, Kazakhstan, Siberia, etc.) and others who have favoured the monotypic theory without making "any attempt to ascertain the range of Cannabis by field studies in these areas or to locate its aboriginal indigenous range" (Emboden, 1981, p. 15)7. Yet, at this point, due to "limited genetic and experimental data, the questions of taxonomy remain unresolved" and some estimate that the "continued monotypic treatment of plants in this genus as C. sativa L. is warranted" (Lynch et al., 2016, p. 350, 358). In fact, even Robert Clarke, who is a partisan of the polytypic theory (Clarke and Merlin, 2016) and is one the world's foremost experts on Cannabis, chose in a recent co-authored article to consider "drug and hemp varieties to be a single species, Cannabis sativa L. with three subspecies - indica, sativa and ruderalis", 
out of "simplicity and because of confusion in the taxonomy of the genus Cannabis" (until genomic analysis finally elucidates the matter once and for all) (Gray et al., 2016, p. 289-290).

10 Therefore, hereafter the choice was made to restrain from using the sativa and indica taxa as well as the sativa and indica labels and focus instead on the varieties/strains that increasingly characterise the global cannabis industry. As a consequence, notwithstanding the fact that it bears no taxonomical validity, I will refer to cannabis varieties/strains as "Cannabis strain + vernacular/commercial name" (for example: Cannabis strain Amnesia Haze), and the single quotation marks that are reserved solely for cultivars (the French hemp cultivar Cannabis 'Fibrimon 21' for example) (Small, 2015, p. 214; Piomelli and Russo, 2016; Pollio, 2016).

\section{How cannabis cultivation and production techniques have been modernised}

The fact that field-based academic research in cannabis producing countries has most often been limited in time, scope, and depth, explains why a large number academics and journalists alike write rather inaccurately not only about the Cannabis plant but also about the many traditional and increasingly modern and diverse cannabis end products: about what herbal cannabis (marihuana, ganja, weed, etc.) is; about what sieved (Afghanistan, Lebanon, Morocco, etc.) and hand-rubbed (India, Nepal) cannabis resin (hashish, chars/charas) is; and about what butane hash oil, rosin, bubble hash, cannabis oil, fresh frozen hash, Ice-O-Lator hash, etc., are (Chouvy and Macfarlane, 2018).

Most of the cannabis that is produced and consumed in the world is herbal cannabis, which is also called marihuana (from Mexican Spanish with possible African origins ${ }^{8}$ ), ganja (from Sanskrit/Hindi with expansion to the Caribbean), weed and pot (from U.S. English), herbe (from French). Herbal cannabis is made of the dried flowers and smallest leaves and stems of the female cannabis plant as the male plants contain much less THC. Since female cannabis plants are most sought after to produce the drug cannabis and since regular cannabis seeds produce approximately $50 \%$ male and $50 \%$ female plants, in the early 1970s skilled North American and European growers crossed a Mexican landrace with landraces from Colombia, Jamaica, Thailand, and India, and started producing sinsemilla (seedless in Spanish) crops by "removing all male plants from their fields, leaving only the unfertilised (therefore seedless) female plants awaiting pollination" (Clarke and Merlin, 2016, p. 308, 309). Yet seedless cannabis had already long been produced in other parts of the world, such as in northeast Thailand (Isan) whose famed "Thai sticks" (dense inflorescences of seedless marihuana bent and tied to the stem of the plant) had become famous in the late 1960s after the Vietnam War introduced U.S. soldiers to Thai cannabis (Maguire and Ritter, 2015).

In Thailand then, but also in India and in other traditional producing countries in the Global South, the removing of male plants to produce seedless cannabis long predated ${ }^{9}$ Mexican and U.S. sinsemilla. It is however most likely the success in the U.S. of the highly potent and expensive Thai cannabis that gave an economic incentive to produce sinsemilla locally in North America. But other incentives to grow cannabis within the United States occurred in the mid-1970s: the end of the Vietnam War in 1975, stricter 
regulations in both Thailand and the United States, the U.S.-sponsored forced eradication of Mexican cannabis fields in the mid-1970s (spayed until 1979 with paraquat, a non-selective herbicide, which raised serious safety concerns among U.S. cannabis consumers), all disrupted exports of foreign cannabis to the United States and, as result, favoured local cannabis production in North America and especially in California. Sinsemilla was reportedly first produced commercially in the early 1970s (if not earlier) in Mexico (hence the name), in Colombia and in Jamaica ${ }^{10}$, before it appeared in California's Humboldt County in the mid-1970s (Richardson and Woods, 1976; Rendon, 2012; Brady, 2013; Maguire and Ritter, 2015; Clarke and Merlin, 2016) ${ }^{11}$. From its inception, then, the modern cannabis economy was very much marked by globalisation as marihuana and hashish were initially imported through transcontinental trade (from Afghanistan, Pakistan, India, Thailand, Lebanon, Morocco, Colombia, Mexico, etc., to the United States, Western Europe, Australia, etc.) and as new and more potent varieties/strains were bred from landraces sourced globally (mostly from the same above-mentioned countries).

Sinsemilla cultivation marked the beginning of a long and complex modernisation process in the cannabis industry that included the creation of the first modern cannabis hybrid, the Skunk \#1, the famous hybrid of "sativa" and "indica" landraces ([Afghan indica x Colombian sativa] x Mexican sativa) that started being bred in 1969 and was first sold in the late 1970s or early 1980s as it took ten growing seasons to produce the "relatively true-breeding seed cultivar"12 (Clarke, 1998; Chouvy and Afsahi, 2014; Clarke and Merlin, 2016, p. 314). It is regarded by many as one of the few "benchmarks of modern marijuana breeding" (Pollan, 2001). Seedless cannabis became even more common in the 1990s when the use of cuttings was introduced and enabled growers to produce only female plants through clones. In the end, "cloning radically changed Cannabis agriculture... by making sinsemilla growing possible and profitable for hobbyists", virtually everywhere in the world (Clarke and Merlin, 2016, p. 309, 313).

The availability of seedless marihuana increased again after 1999, when selective breeding succeeded (in The Netherlands) producing "all-female" cannabis seeds that generate $95 \%+$ female plants and that made the production of seedless cannabis easier when the crops were cultivated out of the reach from airborne male pollen (especially indoors) (Chouvy and Macfarlane, 2018). Cannabis breeders, especially in the United States, The Netherlands, and Spain, have also created auto-flowering strains that flower independently of light cycles and temperature changes and allow for worry-free bountiful harvest (Clarke and Merlin, 2016, p. 317). Last but not least, cannabis potency has largely increased in the past decades as a result of selective breeding, indoor cultivation, and production of seedless cannabis: in the early 1990s, the average THC content in confiscated cannabis samples in the United States was roughly 3.7 percent for seeded herbal cannabis and 7.5 percent for sinsemilla compared to, respectively, 9.6 percent and 16 percent in $2013^{13}$.

16 Such changes in cultivation and production techniques took place gradually after the late 1970s, when "virtually all the marijuana consumed in America [i.e. the U.S.] was imported", as a result, among other factors, of "the Federal war on drugs, which gave the domestic industry a leg up by protecting it from foreign imports and providing a spur to innovation" (Pollan 1995). Indeed "law enforcement makes large-scale production difficult [...] so growers had to figure out a way to make a living with a smaller but better-quality crop" (Mark Kleinman quoted in Pollan 1995; Johnson 2017, 
p. 106-108). In the last few decades, cannabis cultivation has become a truly global phenomenon, with indoor cultivation of modern potent hybrids now possible both indoors and outdoors anywhere in the world, even outside of favourable edaphic and climatic conditions as long as a reliable electric grid is available. Transcontinental trafficking of marihuana has therefore largely been replaced by intraregional trade and import substitution schemes (Decorte et al., 2011; Chouvy, 2016a).

The other most common drug cannabis by-product is hashish (from the Arabic for grass) or cannabis resin: a more or less pliable paste-like substance (depending on both preparation and ambient temperature) obtained by compressing the resin glands, or trichomes, of the female cannabis plant (Clarke, 1998, p. 372-373, 370; Chouvy and Macfarlane, 2018). It can be produced through two different processes, depending on techniques employed in various production areas. In Morocco, the resin glands of the cannabis inflorescences are collected by a threshing and sieving process after the plant has been harvested and dried. The resin is then simply pressed. Sieving is also the technique favoured in the Bekaa valley, in Lebanon, where the renowned Red Lebanon hashish was produced in large quantities up until the early 1990s, and where Moroccan hashish-making techniques (threshing and/or sieving) were most likely, but indirectly, imported from (Clarke, 1998, p. 224).

18 It is possible that the technique was initially imported from Afghanistan (Clarke, 1998, p. 1972) where sieved hashish, called chars (made from pressed sieved resin or garda: gard means dust in Dari but also in Pashto), is still produced. Yet in Afghanistan, to the difference of Morocco and Lebanon, the sieved resin is heated and kneaded repeatedly before being pressed and hand-rolled, a process that is now sometimes mechanised (UNODC, 2010). The other technique, used only in some parts of Asia, is the handrubbing one: much less technical ${ }^{14}$ than sieving, it consists of rubbing the cannabis inflorescences back and forth between the palms and fingers until the resin builds up on the skin and is collected in a ball. Such a process occurs only in India (except in Kashmir where sieved hashish is produced) and Nepal, where hashish is called charas (despite the fact that the word most likely originated from Persian and first referred to sieved hashish ${ }^{15}$ ). Bhang, an edible paste-like preparation of cannabis, traditionally used in foods and drinks, especially during some Hindu and/or Sikh religious occasions (Holi, Janmashtami, Mahashivatri), is also produced in India, and only there (bhang can also refer directly to the cannabis plant, as was already the case with the occurrence of the Vedic Sanskrit bhanga in the Atharvaveda or fourth Veda, written between 1500 and 1000 BCE) (Bouquet, 1950).

19 Next to these traditional cannabis by-products, there is now a vast array of more modern and potent end products that are becoming increasingly popular, especially in the Global North (although their production is already well entrenched in countries such as Morocco). This is the case of butane hash oil (BHO), a solvent-extracted, cannabis resin concentrate made with liquid butane forced through an open or closed loop system. Another modern end product is rosin, a solvent-less extract made by combining heat and pressure through the use of a heating hydraulic press known as a rosin press. Also, more modern extraction processes have been devised to produce high-quality and highly pure hashish by retrieving cannabis trichomes in highly efficient mechanical processes (using for example the Pollinator and the Ice-O-Lator invented in the mid-1990s by Mila Jansen in The Netherlands: Jansen 2018). 
In Morocco for example, where traditional production of sieved hashish remains largely prevalent, modern production techniques are quickly developing, giving rise to very high yields of high-quality sieved hashish and various modern "cannabis extracts" of higher purity, quality and potency (Chouvy and Macfarlane, 2018). At approximately 70 kilograms per hectare, the potential yield of such a high-quality hashish (produced from Cannabis strain Clementine Kush in this case) is significant, compared to the gross estimate of about 15 kilograms per hectare of lower-quality hashish produced on average from kif (the Moroccan landrace) and by way of threshing and sieving (Chouvy and Macfarlane, 2018). Hashish as pure as 95 percent ( $95 \%$ of glandular trichome heads and only 5 percent of contaminants such as plant debris, dust, etc.) with a THC content as high as 68 percent (with the remaining 32 percent being composed of trace amounts of other cannabinoids, as well as terpenes, waxes and plant debris) can now be produced in Morocco. Such a high-quality production is only made possible with seeds imported from European seed breeders and, for the time being, with the technical guidance and financial help of Westerners who then export their products to Western Europe (Chouvy and Macfarlane, 2018). As a result, a 2017 study concluded that "the potency of both resin and herbal cannabis seized in France has increased for the last 25 years", with the THC content of cannabis resin rising slowly from 1992 to 2011, "which is in line with other studies in Europe and Morocco", and then dramatically increasing until 2016 with "a 92 \% growth in mean THC content from 2011 to mid-2016" (Dujourdy and Besacier, 2017, p. 79, 72, 73).

21 The fact that the adoption of such agricultural innovations is happening in Morocco (and apparently not in Afghanistan, India, or Lebanon for example) mostly at the hand of Western (and especially European: Dutch, Spanish, Italians, French, etc.) investors and producers can be explained by various factors: the fact that hashish production had already been initiated by Europeans in the 1960s; that the growth of industry had been spurred by the growing European demand in the 1980s and 1990s; that the hashish industry has then been much less affected than the marihuana industry by import substitution schemes; and by the fact Morocco has long been the world's leading hashish producing country with privileged economic, political, linguistic and cultural links to Western Europe (French and Spanish Protectorates, geographical proximity, etc.). It is significant that cannabis seed companies established in Spain in the early 2000s have played an important role in Morocco, as many Spanish cannabis social clubs buy Moroccan hashish produced from modern hybrid seeds imported from Spain (most recently: Cannabis strain Amnesia Haze, Critical Mass ${ }^{16}$, etc.). Here, again, globalisation has played favourably and repeatedly in the development of the illegal cannabis industry: starting in the 1960s with the Hippie Trail that ran through Morocco, Lebanon, Afghanistan, India, and Thailand (mostly hashish, except for Thailand), and extended to most of the world's surf spots (Australia, Bali, Biarritz, Hawaii, etc.) (mostly marihuana) (Maguire and Ritter, 2015), the spread of cannabis varieties/strains, knowledge, techniques, and end products has reached a truly global dimension since the 2000s with the increasing involvement of Western cannabis breeders and growers in Albania, Colombia, India, Jamaica, Morocco, South Africa, to name but a few places where modern cannabis production is now fast developing (based on knowledge now also widely available through the Web) (sources: author's fieldwork, and interviews and discussions with breeders / growers and police in various countries). 


\section{What do we know about illegal cannabis cultivation in the world and how?}

Estimates of what is mostly an illegal agricultural production (except where the fibreproducing plant and, sometimes, the drug-producing plant, is legal - or decriminalised) are of course difficult and controversial. Satellite detection of outdoor cannabis crops proves more difficult, technically, than that of opium poppies, and such imagery is rarely resorted to, notably because of its $\operatorname{cost}^{17}$. On the other hand, indoor cannabis crops have fast developed during the past decades, whether in the United States, Canada, or Western Europe, and the scale of such crops proves very difficult to assess (estimates and eradication reports actually mention numbers or weight of indoor plants and not cultivated areas). Also, ground surveys are often deemed too expensive (or time-consuming, dangerous, etc.) to carry out as cannabis crops can be grown virtually anywhere and are often much more dispersed than coca or opium poppy crops in a given country (cannabis being an extremely popular drug that has benefited notably from important subcultures (Rubin, 1975, p. 1; Decorte et al., 2011, p. 4-6).

As a result, "most countries provide estimates based on some extrapolations from their cannabis eradication activities" (Legget and Pietschmann, 2008, p. 191). Despite the fact that cannabis researchers affiliated to the United Nations Office on Drugs and Crime (UNODC) have argued that "a few countries have scientifically valid estimates based on remote sensing technology or based on ground surveys", even the most elaborate estimates that were conducted by the UNODC in Afghanistan and Morocco have proven problematic and unreliable (due to theoretical, methodological, technical, logistical, and sometimes even political, issues) (Chouvy and Afsahi, 2014; Chouvy, 2016a). As stated by the UNODC in 2017, "the extent and trends in cannabis cultivation and production are difficult to assess" not only because of "the absence of systematic measurements" (i.e. direct indicators: remote sensing and ground surveys) but also because "most indirect indicators [such as seizures] come from law enforcement authorities and, to a certain extent, reflect their priorities and resources" (UNODC, 2017, p. 37). But such indirect indicators are also of little value because eradication efforts vary between countries and between years in a given country.

Morocco's northern Rif region (14,000 $\mathrm{km}^{2}$ according to the UNODC in 2003), where cannabis cultivation is circumscribed and where the world's most comprehensive surveys have been conducted, reportedly eradicated 8,000 hectares of cannabis in 2011, 5,000 hectares in 2013, 1,147 hectares in 2015, and 395 hectares in 2016 (UNODC, 2013-2018). The Moroccan authorities allegedly reduced their eradication operations in reaction to the Arab Spring and to anti-eradication demonstrations and unrest but if the harvestable areas are logically affected by eradication efforts, the cultivated areas (before eradication) appear surprisingly stable and as such unrepresentative of the state's repressive efforts, especially between 2013 and 2016: 55,500 hectares in 2011, 47,196 hectares in 2013, 47,000 hectares in 2015 and in 2016 (UNODC, 2013-2018).

In India, where cannabis grows wild throughout the country and where cultivation is widespread (from north to south) but unaccounted for (as no cannabis surveys have ever been conducted in the country), the authorities reportedly eradicated only 3,441 hectares in 2016 and 3,446 hectares in 2017 on a territory seven times larger than Morocco and 165 times larger than the Rif region (where cannabis cultivation is circumscribed) (UNODC, 2018; NCB, 2017). While no official estimates of cannabis 
cultivation exist in India, where cannabis by-products such as ganja, charas, and bhang have been widely consumed for centuries both recreationally and religiously nationwide, a guesstimate by a former Narcotics Control Bureau (NCB) superintendent mentioned about 2,100 hectares of cannabis in the famed Himalayan Parvati Valley of Himachal Pradesh in 2013 and a hashish output of 100 to 150 tons in the entire state in $2018^{18}$.

Despite the global scale of illegal cannabis cultivation, the paucity of robust data on its production and trade, even in the countries that are best studied (such as Morocco), is such that that it hinders effective policy and programmatic responses (Leggett, 2006, p. 1; Chouvy and Afsahi, 2014). Estimates of the scale of cannabis cultivation provided by national states, the UNODC or the United States International Narcotics Control Strategy Reports (INCSR) are both unreliable and imprecise. The ground surveys that have been conducted by both national and international agencies for estimating the scale of cultivation have been found wanting, proven expensive, time consuming, and the results have been challenged by a range of officials and academics (Chouvy and Afsahi, 2014; Chouvy, 2016a; Legget and Pietschmann, 2008; Mansfield, 2016; etc.). To date the use of remote sensing in cannabis surveys has also proven challenging with weak spectral signature, crop confusion, variable seasonality, and the crop's diffusion within a single country rendering the estimates too costly and ultimately lacking credibility (Legget and Pietschmann, 2008, p. 191; Walthall and Daughtry, 2003). Data on the scale and nature of hashish production (the second most consumed cannabis byproduct and illegal drug in the EU) is also grossly inadequate and while nearly all of the hashish consumed in Europe is produced in Morocco, Afghanistan, and Lebanon (with Morocco being the source of the overwhelming majority of it) very little to nothing is known about the quantities produced in each country, or indeed the qualitative nature of the end products (Chouvy, 2016a).

There is also a paucity of empirical research on the farmers that cultivate cannabis and their communities in source countries. There are few insights for example with regard to: the role that cannabis plays in the livelihoods of rural populations and the importance of the crop to the local economy; evidence of new cultivation and production practices and technologies and how these impact both on the local politicaleconomy and the long term sustainability of production and the environmental base; and how local producers in source countries interact and work with the growing cannabis economy in Europe (Chouvy and Afsahi, 2014; Chouvy, 2016a; Mansfield, 2016; Chouvy and Macfarlane, 2018).

\section{How this special issues fills some of the blanks on the map}

As explained earlier, the world geography of cannabis is lacking in many respects and it is impossible on the basis of current knowledge to determine the global extent of cannabis cultivation and, consequently, the global amounts of cannabis by-products. What is known is that cannabis cultivation was reported (to the UNODC by Member States) in 135 countries in the period 2010-2015, with Morocco being the country most reported as the source of cannabis resin, followed by Afghanistan and, to a lesser extent, Lebanon, India, and Pakistan. Sources of herbal cannabis are more difficult to assess as trafficking is mostly intraregional and the UNODC only reports sources by 
region: the most mentioned sources are Mexico and Canada in North America; Colombia, Paraguay and Jamaica in South America and the Caribbean; Nigeria, Mozambique and Ghana in Africa; Afghanistan, Kyrgyzstan, Myanmar and Laos in Asia; and the Netherlands and Albania (at least until the late 2010s) in Europe. Yet the UNODC clearly states that this does not mean that Mexico, for example, is the largest producer of cannabis in North America since the "significant amounts" produced in the United States are mostly destined to domestic consumption and not for export (UNODC, 2017, p. 47).

In the end, source reports are a clear example of how unreliable and worthless drugrelated data often are: the fact that the geographic origins of the cannabis resins seized in Europe seem to be determined not by scientific analyses of the resins but by the testimony of offenders during their custody is problematic since this methodology is clearly unreliable (Chouvy, 2016a). Also, as indicated by the UNODC, "source countries might not always mention the country where it [cannabis resin] was produced and might also indicate the latest known transit country": this is obviously something that further affects the quality of data already proved unreliable (UNODC, 2011, p. 190). Unsurprisingly, while it is impossible to reasonably estimate which countries are the world's leading illegal cannabis producers, it is easier to list which countries are legal producers of recreational and/or medical cannabis. Things have evolved very quickly during the last few years and legalisation of recreational and/or medical cannabis has occurred in about 10 countries in 2018 alone.

As of the $1^{\text {st }}$ of January 2019 the consumption and sale of recreational cannabis was legal in two countries only: in Uruguay since 2013 and in Canada since 2018. South Africa is due to legalise the private production and use of cannabis (public use, selling and supplying will remain illegal) by 2020 after a 2018 ruling by the Constitutional Court. Cannabis is also allegedly legal in North Korea but very little is known about the country (Chouvy, 2016b). In 2018 recreational cannabis was still illegal under federal law in the United States but was legal (since 2012 in Colorado and Washington) in the ten following states: Alaska, California, Colorado, Maine, Massachusetts, Michigan, Nevada, Oregon, Vermont, and Washington) ${ }^{19}$.

31 Medical cannabis has been partially or fully legalised (with or without prescription) in 36 countries: Argentina, Australia, Canada, Chile, Colombia, Croatia, Cyprus, Czech Republic, Denmark, Finland, Georgia, Germany, Greece, Israel, Italy, Jamaica, Lesotho, Luxembourg, Macedonia, Malta, Mexico, Norway, Peru, San Marino, The Philippines, Poland, Portugal, South Africa, South Korea, Sri Lanka, Switzerland, United Kingdom, Turkey, Uruguay, Vanuatu, Zimbabwe. In December 2018 Thailand has decided to join what is now a fast-growing global movement and even France, an extremely conservative country when it comes to cannabis, has opened the door to examining the medical benefits of cannabis. In the United States, starting in 1996 with California, 33 states plus Guam, Puerto Rico, the Northern Mariana Islands, the U.S. Virgin Islands, and the District of Columbia have legalized medical cannabis. CBD, one of the most sought-after medical cannabinoids, has been legalized in the United States in December 2018 due to changes in the Farm Bill. In the European Union, the latest developments include the vote on 14 February 2019 by the European Parliament, following reports about the World Health Organization (WHO) recommending a rescheduling of cannabis and several of its key components under international drug treaties ${ }^{20}$, on a resolution that "calls on the Commission and member states to address regulatory barriers which 
burden scientific research and invites them to properly fund research and promote greater knowledge of medical cannabis among medical professionals" ${ }^{21}$.

As for hemp, the non-psychoactive cannabis valued as a source of fibre, oils, and seeds, it is legally cultivated in 25 countries (Australia, Austria, Canada, Chile, China, Denmark, Egypt, Finland, France, Germany, Great Britain, Hungary, India, Nepal, Poland, Portugal, Romania, Russia, Slovenia, South Korea, Spain, Switzerland, Thailand, Ukraine) but has been illegal in the United States between the 1950s (it was an important legal crop before that) and 2018. The 2014 Farm Bill had first allowed hemp cultivation for research purposes only, and for not commercial production, but the 2018 Farm Bill eventually marked a major shift in U.S. agriculture and drug policy by lifting the ban on hemp and amending the Controlled Substance Act of 1970 for the first time to legalize CBD (though not medically) and the other cannabinoids that can be sourced from hemp (less than $0.3 \%$ of THC by dry weight).

While the United Kingdom was the world's leading producer of medical cannabis in 2016, the fact that Canada legalised recreational cannabis production and uses in 2018 (after legalising medical cannabis in 2001) is about to turn the north American state into one of the world's leading cannabis producers, notably because it now benefits from limited competition in global medical cannabis exports (although countries in Latin America will benefit from a more favourable climate with lower production costs and much lower carbon footprint ${ }^{22}$ ), from the difficulties faced by other nations to find safe and legal supplies of medical cannabis, and from having gained first mover advantage into emerging medical cannabis markets such as Australia, Brazil, Chile, Croatia, Germany, Italy, etc. In fact, Canada's seven biggest licensed producers can potentially produce up to 2,200 tonnes of (processed) cannabis a year, eventually leading the country to dominate the global cannabis market (with a total production estimated to 3,000 tonnes a year by 2020) if nothing is done to end the federal prohibition in the United States ${ }^{23}$. 


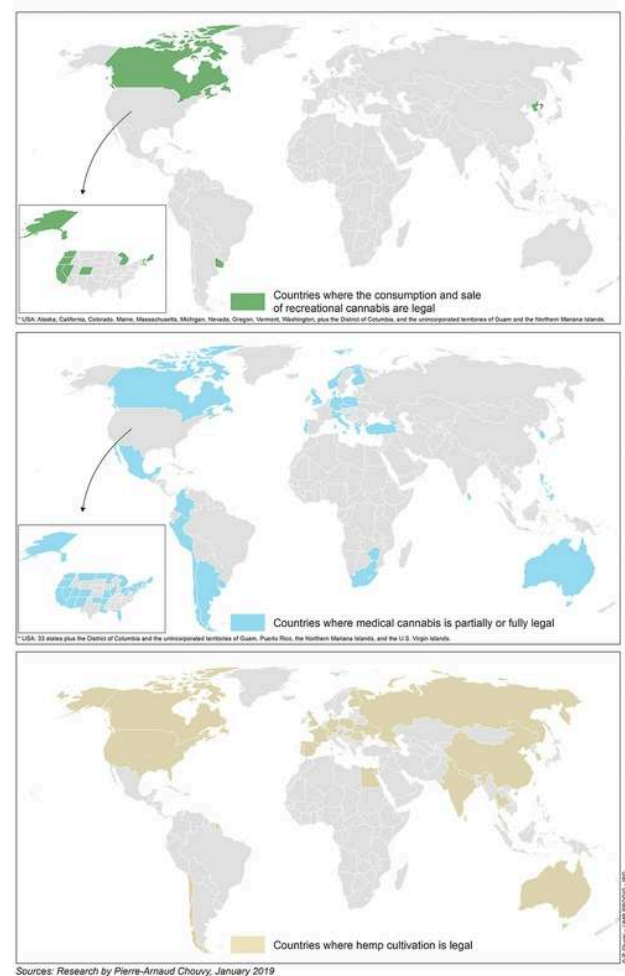

\section{From shadowy past to uncertain future}

During the 2010s the quasi-total prohibition of cannabis has been seriously questioned and even abolished in various countries and states, with recreational, medical, and other uses (notably with hemp being increasingly used as building material), being legalised, and sometimes only decriminalised, on every continent. The speed and scale at which what is truly a global phenomenon occurred has revealed how little is known about the plant, its (geo)history, its uses and its safety or associated risks. From the plant's taxonomy to its medical potential, much still needs to be studied and understood. Of course, the geography of cannabis will also benefit from its legalisation as the plant, its production, trade, and uses, have been very little studied because of prohibition and the risks and dangers that such a research topic has long represented (Chouvy, 2018).

While much needs to be learned about the past and even the present of cannabis production and uses in the world, the real urgency lies in understanding what the future holds now that legalisation is well under way and is spreading fast. Indeed, the future of the world's varied cannabis industries is very uncertain as the ongoing farming and legislative changes are going to affect the way the global, regional and national markets have been structured during decades. New North-South but also North-North and South-South dynamics are about to emerge as some countries and some states have legalised recreational and/or medical cannabis. Also, the recent adoption of modern high-yielding varieties and farming techniques (modernisation of cannabis cultivation and of production of cannabis by-products) will necessarily impact the global map of cannabis cultivation, with economic (further impoverishment of 
some the resource-poor cannabis farmers, collection of indigenous germplasm and threat posed to landraces by modern hybrids), socio-political (unrest, contestation, repression, etc.), and environmental (water depletion, soil exhaustion, loss of landraces, heavy carbon footprint of modern indoor cannabis cultivation, etc.) consequences. Disruptions and reorganisations in the global and regional cannabis markets have already taken place on numerous occasions of course (since the 1960s) but faster and deeper changes are now to be expected.

In fact, the legalisation that took place in some U.S. states has already created unintended consequences in Mexico, with a shift from cannabis production to heroin and methamphetamine production provoked by the halving of Mexican cannabis prices at the farm gate. Also, with the removal of the competitive advantage of illegality, the U.S. Drug Enforcement Administration has reported that Mexican cannabis growers now strive to produce higher-quality cannabis to match U.S. demand and even that, for the first time ever, U.S. cannabis was being trafficked into Mexico ${ }^{24}$.

After having already suffered from the brunt of the war on drugs other major cannabis producers in the Global South are likely to bear the consequences of legalisation changes taking place in their Western markets: for example, Moroccan cannabis farmers from the Rif will most likely greatly suffer from the legalisation that will eventually and inevitably take place in Western Europe. The main competitive advantage of Moroccan cannabis farmers is clearly the fact that production is illegal in both Europe and Morocco and that this illegal industry is tolerated by the Moroccan state. While the terroir was also clearly an advantage but was offset by lower-quality hashish production (actually allowed by the same competitive advantage of illegality and the laws of supply and demand), when legalisation will happen in Europe, the Rif and its farmers will see their survival economy seriously contract if not collapse. Considering how poor and politically fragile countries like Mexico and Morocco are, the disruptive impacts and consequences of legalisation should not be ignored.

But the changes to come are not only economic. They are also botanical and ethical. Indeed, Western seed breeders have long collected germplasm from African, Asian, and South American landraces (without making "efforts to preserve international property rights potentially embedded in landraces" and without sharing benefits) to breed thousands of commercial hybrids that now happen to be sold to and grown in the Global South where landraces are increasingly at risks of being replaced by modern commercial hybrids, as is already happening in Morocco and to a lesser extent in India. (Duvall, 2016, p. 20; Chouvy and Macfarlane, 2018). As explained by Clarke and Merlin (2015, p. 301), "many NLD/BLD hybrid seeds were produced in Western countries and some did interbreed with original ancestral populations" after "well-meaning travellers visited many regions where NLD landraces were still growing, gave modern hybrid seeds to local farmers, who hoping for economic benefit, crossed them with their traditional landraces". As a result, "original pure NLD landraces have become rare in all traditional marijuana producing countries" and, during the past decade or so, a worldwide bioprospecting race has been launched by seed breeding companies to collect rare and sometimes fast-disappearing landraces, including Morocco's elusive kif (personal contacts with bioprospectors).

While it is obvious that legalisation at various scales will allow the global cannabis production and economy to grow tremendously and the research on cannabis to finally develop and improve (in social sciences of course but also in botany, in medicine, and 
in pharmaceuticals), especially in the Global North, it is difficult at this stage to foresee what the future holds for the countless cannabis farmers of the Global South who will see their individual, regional, and national economies bear the brunt of global competition once the competitive advantage of illegality has been supressed. The same is actually true of former outlaw growers from the Global North who attempt to transition to legal production where legalisation has taken place: such is the case in the famed Humboldt Country of Northern California (where legalisation took place in January 2018) where the vast majority of growers have immediately suffered from the state's stiff regulatory demands (laws and taxation of an industry that has obviously never before being regulated), from a quickly oversaturated market, from the competition of a persistent illegal market (competitive for not paying the high cost of legality), and from corporate so-called Big Marihuana ${ }^{25}$. As explained by Peter Maguire and Mike Ritter in their book about the trafficking of Thai marihuana to the United States (early 1970s to late 1980s), "ironically, today the biggest opponents of marijuana legalisation are not law enforcement agents but some of the black market growers and smugglers, because their pricing structure would collapse" (Maguire and Ritter, 2015, p.172, 181) While over a century of prohibition and decades of a costly and counterproductive war on drugs have done clearly more harm than good to illegal cannabis resource-poor farmers worldwide, it now remains to be seen how legalisation and open competition will affect them, whether in the Global North or in the Global South.

\section{BIBLIOGRAPHY}

Bouquet R.J., 1950. Cannabis. Bulletin on Narcotics, $\mathrm{n}^{\circ}$ 4, p. 14-30.

Brady E. 2013. Humboldt. Life on America's Marijuana Frontier. New York, Grand Central Publishing.

Chouvy P.-A., 2008. Production de cannabis et de haschich au Maroc : contexte et enjeux. L'espace politique, $\mathrm{n}^{\circ} 4$, p. 5-19.

Chouvy P.-A., 2016a. The Supply of Hashish to Europe. Background paper commissioned by the EMCDDA for the 2016 EU Drug Markets Report. European Monitoring Centre for Drugs and Drug Addiction, Lisbon, EMCDDA, April 2016.

Chouvy P.-A., 2016b. The Myth of the Narco-State. Space and Polity, vol. 20, $\mathrm{n}^{\circ} 1$ (Special issue on Drugs, law, people, place and the state: ongoing regulation, resistance and change, ed. by Barney Warf and Stewart Williams), p. 26-38.

Chouvy P.-A., 2016c. Himalayan Highs. Cannabis Now Magazine, Issue 19, March 2016, p. 42-46.

Chouvy P.-A., 2018. De la recherche de terrain sur la production agricole illégale de drogue. L'Espace Politique, vol. $35 n^{\circ}$ 2. http://journals.openedition.org/espacepolitique/5372

Chouvy P.-A., Afsahi K., 2014. Hashish Revival in Morocco. International Journal of Drug Policy, 25:3, p. 416-423. 
Chouvy P.-A., Macfarlane J., 2018. Agricultural Innovations in Morocco's Cannabis Industry. International Journal of Drug Policy, vol. 58, p. 85-91.

Clarke R.C., 1998. Hashish! Los Angeles, Red Eye Press.

Clarke R.C., Merlin, M. D., 2013. Cannabis: Evolution and Ethnobotany. Los Angeles and Berkeley, University of California Press.

Clarke R.C., Merlin M. D., 2015. Letter to the Editor: Small, Ernest. 2015. Evolution and Classification of Cannabis sativa (Marijuana, Hemp) in Relation to Human Utilization. Botanical Review, vol. 81, n³, 189-294. Botanical Review, vol. 81, n 3, p. 295-305.

Clarke R.C., Merlin M., 2016. Cannabis Domestication, Breeding History, Present-day Genetic Diversity, and Future Prospects. Critical Reviews in Plant Sciences, vol. 35, n 5-6, p. 293-327.

Decorte T., Potter G.R., Bouchard M., 2011. World Wide Weed: Global Trends in Cannabis Cultivation and its Control. Farnham, Ashgate Publishing.

Decorte T., Potter G.R., Bouchard M., 2011. The Globalization of Cannabis Cultivation. In Decorte T., Potter G.R., Bouchard M., World Wide Weed: Global Trends in Cannabis Cultivation and its Control. Farnham, Ashgate Publishing, p. 1-22.

Dufton E., 2017. Grass Roots: The Rise and Fall and Rise of Marijuana in America. New York, Basic Books.

Dujourdy L., Besacier F., 2017. A study of cannabis potency in France over a 25 years period (1992-2016). Forensic Science International, vol. 272, p. 72-80.

Duvall C., 2014. Cannabis. London, Reaktion Books.

Duvall C., 2016. Drug laws, bioprospecting and the agricultural heritage of Cannabis in Africa. Space \& Polity, vol. 20, $\mathrm{n}^{\circ} 1$, p. 10-25.

Duvall C., 2019. The African Roots of Marijuana. Durham, NC, Duke University Press.

Emboden W.A., 1981. The Genus Cannabis and the Correct Use of Taxonomic Categories. Journal of Psychoactive Drugs, vol. 13, n 1, p. 15-21.

Gray D.J., Clarke R.C., Trigiano R.N., 2017. Introduction to the Special Issue on Cannabis. Critical Reviews in Plant Sciences, vol. 35, n 5-6, p. 289-292.

Hillig K.W., 2005. A Systematic Investigation of Cannabis. PhD Dissertation, Doctorate of Philosophy in the Department of Biology, Indiana University.

Jansen M., 2018. How I Became the Hash Queen. Paris, Mama Editions.

Johnson N., 2017. Grass Roots: A History of Cannabis in the American West. Corvallis, Oregon State University Press.

Legget T., 2006. Review of the world cannabis situation. Bulletin on Narcotics, vol. LVIII, $\mathrm{n}^{\circ} 1$ and 2.

Legget T., Pietschmann T., 2008. Global cannabis cultivation and trafficking. In A cannabis reader: global issues and local experiences, Monograph series 8, Volume 1, European Monitoring Centre for Drugs and Drug Addiction, Lisbon, p. 189-212.

Lynch R.C., Vergara D., Tittes S., White K., Schwartz C. J., Gibbs M.J., Ruthenburg T.C., de Cesare K., Land D.P., Kane N.C., 2016. Genomic and Chemical Diversity in Cannabis. Critical Reviews in Plant Sciences, vol. 35, n 5-6, p. 349-363.

Maguire P., Ritter M., 2015. Thai Sticks. Surfers, Scammers, and the Untold Story of the Marijuana Trade. New York, Columbia University Press. 
Mansfield D., 2016. A State Built on Sand: How Opium Undermined Afghanistan. New York, Oxford University Press.

Marks H., 1998. Mr. Nice. An Autobiography. London, Vintage.

Meijer E.P.M. de., 1995. Fibre hemp cultivars: A survey of origin, ancestry, availability and brief agronomic characteristics. Journal of the International Hemp Association, vol. 2, n² 2, p. 66-73.

Mills A., 2012. The carbon footprint of indoor Cannabis production. Energy Policy, n 46, p. 58-67. Narcotics Control Bureau (NCB), 2017. Narcotics Control Bureau Annual Report 2017. Ministry of Home Affairs, Government of India, New Delhi, Narcotics Control Bureau.

Piomelli D., Russo E.B., 2016. The Cannabis sativa versus Cannabis indica debate: an Interview with Ethan Russo, MD. Cannabis and Cannabinoid Research, vol. 1, n 1, p. 44-46.

Pollan M., 1995. How Pot Has Grown. The New York Times Magazine. 19 February.

Pollan M., 2001. The Botany of Desire. A Plant's-Eye View of the World. New York, Random House.

Pollio A., 2016. The name of Cannabis: a short guide for nonbotanists. Cannabis and Cannabinoid Research, vol. 1, n 1, p. 234-238.

Richardson J., Woods A. 1976. Sinsemilla: Marijuana Flowers. Berkeley, And/Or.

Rendon J., 2012. Super Charged. How Outlaws, Hippies and Scientists Reinvented Marijuana. Portland \& London, Timber Press.

Rubin V.R., (ed), 1975. Cannabis and Culture. The Hague - Paris, Mouton Publishers.

Rubin V.R., 1975. Introduction. In Rubin V.R. (ed), 1975. Cannabis and Culture. The Hague - Paris, Mouton Publishers, p. 1-10.

Sawler J., Stout J.M., Gardner K.M., Hudson D., Vidmar J., Butler L., Page J.E., Myles S., 2015. The Genetic Structure of Marijuana and Hemp. PLoS One, vol. 10, n 8, e0133292.

Schultes R.E., Klein, W.M., Plowman, T., Lockwood, T.E., 1975. Cannabis: An Example of Taxonomic Neglect. In Rubin V. (ed), Cannabis and Culture. Paris, Mouton.

Servel H., Zurayk R., 2014. Marché, pouvoir et jeux de rôle : le Rouge libanais résiste dans la vallée de la Beqaa. Actes du colloque international SFER AGP 2014. Guyancourt, 12 février 2014.

Small E., 2015. Evolution and Classification of Cannabis sativa (Marijuana, Hemp) in Relation to Human Utilization. The Botanical Review, vol. 81, n³, p. 189-294.

Small E., Cronquist A., 1976. A Practical and Natural Taxonomy for Cannabis. Taxon, vol. 25, n 4, p. $405-435$.

Steinberg M.K., Hobbs J.J., Mathewson K., 2004. Dangerous Harvests: Drug Plants and the Transformation of Indigenous Landscapes. Oxford, Oxford University Press.

Stoa R. 2018. Craft Weed: Family Farming and the Future of the Marijuana Industry. Cambridge, Massachusetts Institute of Technology.

Taylor J.S., Jasparro C., Mattson K., 2013. Geographers and Drugs: A Survey of the Literature. Geographical Review, vol. 103, n³ 3. p. 415-430.

United Nations Office on Drugs and Crime (UNODC), 2007. Maroc. Enquête sur le cannabis 2005. Vienne, United Nations.

United Nations Office on Drugs and Crime (UNODC), 2010. Afghanistan Cannabis Survey 2009. Vienna, United Nations. 
United Nations Office on Drugs and Crime (UNODC), 2011. World Drug Report 2011. Vienna, United Nations.

United Nations Office on Drugs and Crime (UNODC), 2012. World Drug Report 2012. Vienna, United Nations.

United Nations Office on Drugs and Crime (UNODC), 2013. World Drug Report 2013. Vienna, United Nations.

United Nations Office on Drugs and Crime (UNODC), 2014. World Drug Report 2014. Vienna, United Nations.

United Nations Office on Drugs and Crime (UNODC), 2015. World Drug Report 2015. Vienna, United Nations.

United Nations Office on Drugs and Crime (UNODC), 2016. World Drug Report 2016. Vienna, United Nations.

Walthall C., Daughtry C., 2003. What do we know about spectral signatures of illegal cannabis cultivation? Communication at the 2003 ONDCP International Technology Symposium, San Diego, CA, July 8-11.

Warf B., 2014. High Points: An Historical Geography of Cannabis. Geographical Review, vol. 104, $\mathrm{n}^{\circ}$ 4, p. 414-438.

\section{NOTES}

1. In pharmacology potency is a measure of drug (not necessarily an active substance or ingredient) activity expressed in terms of the amount required to produce an effect of given intensity. Therefore, in equivalent quantities, highly potent marihuana or hashish will have stronger effects (the so-called high) than lower potency marihuana or hashish.

2. In this text "marihuana" and "hashish" are used as generic terms for herbal cannabis and cannabis resin, regardless of how and where they are produced. More details are provided below in the text about how such cannabis by-products vary and how they are referred to in different regions.

3. https://www.leafly.com/explore/sort-alpha (consulted on 4 June 2018 and 28 June 2019).

4. Delta-9-tetrahydrocannabinol (THC) is the cannabinoid (chemical compound) responsible for most of the psychoactive effects of cannabis but also for analgesic, antiemetic, antispasticity, anxiolytic, and other medical effects.

5. Cannabidiol is the cannabinoid responsible for anti-inflammatory, analgesic, anxiolytic, and anti-epileptic effects among others. CBD is also contained in small quantities in some Asian hops varieties (Humulus kriya).

6. Therefore, the deficit of primary field-based research in cannabis growing areas is problematic not only in social sciences.

7. See Duvall, 2019 for a highly useful summary of recent taxonomic developments.

8. See Duvall, 2019 about the etymology of marihuana (from Bantu mariamba): the author explains how the plant drug (seeds) came to the New World (Brazil) across the Atlantic Ocean primarily from Central Africa - through the slave trade - and how "its primary New World names reflect this geography". See also Duvall, 2019 about the phonetical incorrectness of marijuana.

9. Garner, F., 2005. Dialogue with the DEA. Counterpunch; 24 December. https:// www.counterpunch.org/2005/12/24/dialogue-with-the-dea/ (consulted on 11 January 2019). Maguire and Ritter mention how a north-eastern Thai cannabis farmer tended to his crop by 
carefully examining his plants for male pollen pods and immediately removing male specimen from his field (Maguire and Ritter, 2015, p. 65).

10. Personal communication by Robert Clarke on 19 June 2019.

11. See also: Blair E., 2011. History of Cannabis Use and Anti-Marijuana Laws in Thailand. 11 July. http://thailawforum.com/history-of-marijuana-cannabis-thailand.html (consulted on 11 January 2019). Maguire P., 2018. Thailand's Legendary Marijuana. 30 April. https://thediplomat.com/ 2018/04/thailands-legendary-marijuana/ (consulted on 11 January 2019). See Clarke and Merlin (2016, p. 300-302) about the history of sinsemilla in the U.S. and note that the book by Richardson and Woods (1976) was the first ever to explain how to produce sinsemilla.

12. Clarke and Merlin use the term cultivar in an unofficial acceptation, unlike Small who I follow here.

13. National Institute on Drug Abuse, A Rise in Marijuana's THC Levels. https:// archives.drugabuse.gov/rise-in-marijuanas-thc-levels (consulted on 20 December 2018).

14. Hand rubbing is less technical than sieving but the use of skilled workers is necessary to produce the very best quality charas (through a very slow and gentle rub that collects only cannabis trichomes and not other vegetal matter): it takes one day to a careful hashish rubber to produce about 5 grams of the very best quality charas (Chouvy, 2016c).

15. Charas is most likely a metonym as sieved hashish produced in the Greater Khorasan from the thirteenth century on was cured and carried in leather pouches called charas by qalandars, wandering ascetic Sufi dervishes who indulge in sacramental hashish intoxication. Hashish from Khorasan was likely first exported to the Indian subcontinent during the Delhi Sultanate (1206-1526) and became popular, notably after Babur, an advocate of charas and majoun (an edible cannabis-based preparation), founded the Mughal Empire in 1526. See https:// therealseedcompany.wordpress.com/2018/11/26/charas-or-hashish-the-straight-dope-on-

cannabis-resin/ (consulted on 12 January 2019) and Bouquet, 1950. It is worth noting that the production of sieved hashish is reportedly increasingly common in India and Nepal (personal testimonials and source above).

16. Critical Mass is a famous and very popular strain created from the hybridisation between a pure Afghani line and one of the most popular hybrids around the world, the aforementioned Skunk \#1 ([Afghan indica x Colombian sativa] x Mexican sativa). Critical Mass has long been being one of the most cultivated cannabis strains in/from Spain (after being "feminised" by Dinafem) and, as a consequence, is now one of the most widely cultivated hybrids in Morocco. Critical Mass belongs to the modern cannabis history and owes its fame notably to the founders of the Mr. Nice Seedbank (founded in 1998) who first produced it: the two legendary Australian cannabis breeders Scott Blakey (a.k.a. Shantibaba) and Nevil Schoenmakers (1956-2019: founder the world's first cannabis seedbank in the early 1980s in the Netherlands), and the famous British hashish (from Afghanistan, Pakistan, Lebanon) trafficker Howard Marks (a.k.a. Mr Nice: 1945-2016). See: Critical Mass by Mr. Nice, a legendary cannabis strain. Alchimia. https:// www.alchimiaweb.com/blogen/marijuana-growing-guide/history-of-marijuana-strains; Vergados, J. 2016. Breeder Diaries: Scott Blakey. Skunk Magazine. June/July, p. 64-70 (https:// cbdcrew.org/scott-blakey-aka-shantibaba-speaks-to-skunk-magazine); and Marks 1998 (consulted on 14 May 2019).

17. Although the spectral signature of cannabis can look separable, the signal classification often conflicts with other land covers (Walthall and Daughtry, 2003). In its 2005 cannabis survey in Morocco, the UNODC explained that the accuracy of their remote sensing approach was "acceptable" and that more precise results proved difficult to obtain since the spectral signature of rain-fed cannabis (kif) did not differ much from that of bare soil (UNODC, 2007, p. 36). In Morocco, the fast spread of irrigated hybrids should now make remote sensing easier and more precise. 
18. Jolly A., 2013. Illegal cannabis and opium cultivation ride high in Parvati Valley in HP. India Today. 6 April. https://www.indiatoday.in/magazine/nation/story/20130408-illegal-cannabisand-opium-cultivation-in-parvati-valley-in-himachal-pradesh-762936-1999-11-30. Plus personal communication by the NCB official on 29 November 2018.

19. See Dufton, 2017 for the most up to date and comprehensive history of marijuana legalisation in the United States of America.

20. Angell T., 2019. World Health Organization Recommends Reclassifying Marijuana Under International Treaties. Forbes. 1 February. https://www.forbes.com/sites/tomangell/2019/02/01/ world-health-organization-recommends-rescheduling-marijuana-under-international-treaties/ \#73ad551b6bcc (consulted on 2 February 2019).

21. Take medical use of cannabis seriously, say MEPs. European Parliament Newsletter. 7 February 2019. http://www.europarl.europa.eu/news/en/agenda/briefing/2019-02-11/10/take-medicaluse-of-cannabis-seriously-say-meps (consulted on 15 February 2019).

22. Nawrat A., 2018. Latin America's medical cannabis market to reach $\$ 8.5$ bn by 2028 . Pharmaceutical Technology. 10 October. https://www.pharmaceutical-technology.com/news/latinamerica-cannabis-report-market-growth/ (consulted on 11 January 2019). See also Mills E., 2012.

23. Williams S., 2018. Canada's Top 7 Marijuana Growers Lost Nearly $\$ 300$ Million This Quarter. The Motley Fool, 20 November, https://bit.ly/2zv7aVG. Williams S., 2018. Predicting the 10 Largest Marijuana Producers in Canada by 2020. The Motley Fool, 23 September, https://bit.ly/2E6ccM0. Hoban R., 2018. Inside Canada's New Cannabis \& Hemp Regulations. Cannabis Now, 17 March, https://bit.ly/2BG1WYK. Tencer D., 2018. U.S. Cannabis Producers Fear Canada Will 'Dominate The Industry'. Huffington Post, 29 September, https://bit.ly/2TYsf38. (consulted on 18 November 2018.

24. Ingraham C., 2016. Legal marijuana is finally doing what the drug war couldn't" The Washington Post, 3 March. https://www.washingtonpost.com/news/wonk/wp/2016/03/03/legalmarijuana-is-finally-doing-what-the-drug-war-couldnt/?noredirect=on\&utm_term=.

$1 \mathrm{~d} 9 \mathrm{aa3e} 04 \mathrm{ac} 8$ (consulted on 11 January 2019). Other unintended consequences are taking place in the United States, with, for example, a contraction of the legal cannabis market in California as "the costs of setting up, licensing, testing and packaging requirements have proved a heavy burden, and revenues haven't flowed in as expected". As a result, "the unrolling of legal adultuse cannabis has reinvigorated the underground market rather than curtailed it" and "the sale of bootleg marijuana is going strong, especially around Mendocino, Humboldt and Trinity counties, known as the Emerald Triangle, where as much as 80 percent of the illegal pot sold in other states is produced": Fimrite P., 2018. 'Death by a thousand cuts:' California's first year of legalized pot is no smooth trip. San Francisco Chronicle, 28 December. https://www.sfchronicle.com/news/article/ Death-by-a-thousand-cuts-California-s-13494193.php\#photo-16694087 (consulted on 11 February 2019).

25. Wilson S., 2018. Outlaw weed comes into the light. Washington Post, 16 March. https:// www.washingtonpost.com/news/national/wp/2018/03/16/feature/californias-outlaw-

marijuana-culture-faces-a-harsh-reckoning-legal-weed/?

noredirect=on\&utm_term=.e619a297522f. Stoa, R. 2018. Big Marijuana vs. craft weed: Will cannabis conglomerates ruin small family farms? Salon, 25 November. See also Stoa, 2018. https://www.salon.com/2018/11/25/big-marijuana-vs-craft-weed-will-cannabis-conglomeratesruin-small-family-farms/ (consulted on 11 February 2019). See also Stoa, 2018. While the threat of large cannabis conglomerates is to be taken seriously, one should not forget that the illegal cannabis industry has long been based on small-scale growers and that the legal cannabis industry is emerging at a time when past experiences with craft beer (for example) have shown that customers recently favoured small-scale artisanal brews over industrial beer, most notably in the United States. Yet the ongoing battle between Big Beer and independently-owned craft beer is an indication that the future of the cannabis industry, and especially of small-scale 
growers, will be complicated. See: Taylor K., 2016. The bathe between Big Beer and craft brewers is getting ugly. Business Insider, 11 February. https://www.businessinsider.fr/us/big-beer-vscraft-beer-battle-gets-ugly-2016-2. Infante D. 2019. How the World's Biggest Brewer Killed the Craft Beer Buzz. Medium. 21 March. https://medium.com/s/story/how-the-worlds-biggestbrewer-killed-the-craft-beer-buzz-e205a28ff632 (consulted on 13 May 2019).

\section{ABSTRACTS}

Despite cannabis being the most common illegal drug crop in the world and its worldwide presence, very little is known about its production, trade, and consumption at the global scale. This is due mostly to over a century of global prohibition and the dangers associated to researching illegal drug crop production. Worse, the limited data available about cannabis cultivation is most often inaccurate, unreliable, and highly controversial. While this has always been problematic, in terms of sheer knowledge and informed policy-making, it has now become even more acute of an issue as global trends towards decriminalisation and legalisation are already provoking negative unintended consequences in poor producing countries. This article is an effort to present the state of the current knowledge and the present and future stakes of the fast-changing cannabis industry and legislation.

\section{INDEX}

Keywords: cannabis, world, production, illegality, legalisation, knowledge

\section{AUTHOR}

\section{PIERRE-ARNAUD CHOUVY}

Pierre-Arnaud Chouvy, pachouvy@geopium.org, is a geographer at the Centre national de la recherche scientifique (CNRS) in Paris, France, UMR 8586 Prodig. He edits www.geopium.org and www.chouvy-geography.com. He recently published:

- Chouvy P.-A., 2018, De la recherche de terrain sur la production agricole illégale de drogue, L'Espace Politique [En ligne], vol. 35, $\mathrm{n}^{\circ}$ 2. http://journals.openedition.org/espacepolitique/5372 - Chouvy P.-A., Macfarlane J., 2018. Agricultural Innovations in Morocco's Cannabis Industry. International Journal of Drug Policy, vol. 58, p. 85-91.

- Chouvy P.-A., 2018. Illegal drug plant cultivation and armed conflicts. Case studies from Asia and Northern Africa. In Zurayk R., Woertz E., Bahn R.A.(ed.), Crisis and Conflict in the Agrarian World: An Evolving Dialectic. Oxon, CABI Publishing, p. 64-72. 